\title{
Laboreal
}

Volume $13 \mathrm{~N}^{\circ} 1$ | 2017

Varia

\section{Saúde : uma relação com o meio e os modos de vida}

Salud : una relación con el medio y los modos de vida

Santé: une relation avec le milieu et les modes de vie

Health : a relationship with the environment and ways of life

\section{Jussara Brito}

\section{OpenEdition}

\section{Journals}

\section{Edição electrónica}

URL: http://journals.openedition.org/laboreal/2018

DOI: 10.4000/laboreal.2018

ISSN: 1646-5237

\section{Editora}

Universidade do Porto

\section{Refêrencia eletrónica}

Jussara Brito, «Saúde : uma relação com o meio e os modos de vida », Laboreal [Online], Volume 13 $N^{0} 1$ | 2017, posto online no dia 01 julho 2017, consultado o 14 setembro 2020. URL : http:// journals.openedition.org/laboreal/2018

Este documento foi criado de forma automática no dia 14 setembro 2020.

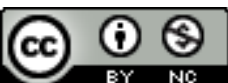

Laboreal está licenciado com uma Licença Creative Commons - Atribuição-NãoComercial 4.0 Internacional. 


\title{
Saúde : uma relação com o meio e os modos de vida
}

\author{
Salud : una relación con el medio y los modos de vida \\ Santé : une relation avec le milieu et les modes de vie \\ Health: a relationship with the environment and ways of life
}

\section{Jussara Brito}

\section{NOTA DO EDITOR}

http://dx.doi.org/10.15667/laborealxiii0117jb

1 Abordar a temática da saúde de forma concisa não é uma tarefa fácil. Trata-se de uma noção que sofre a influência dos valores (inclusive no plano individual), das concepções filosóficas, científicas e religiosas, como também dos contextos culturais, sociais e econômico-políticos específicos, variando conforme o lugar e a época (Scliar, 2007). Mais do que isso, conforme sinaliza Sabroza (2001), não permite uma definição objetiva a partir de elementos aceitos universalmente, devendo ser incluído entre aqueles conceitos que são considerados imprecisos. Sua marca é, portanto, a fluidez.

2 Do ponto de vista histórico-social, no Ocidente, com a estruturação do modelo biomédico (meados do século XIX), o corpo passou a ser visto de forma fragmentada, buscando-se evidências de mudanças anatomofisiológicas capazes de explicar o adoecimento. Na ausência de doença constatada, o corpo estaria saudável. Não obstante a forte e persistente aceitação do referido modelo, já no início do século XX observou-se a emergência de críticas a tais explicações, qualificadas como mecanicistas e redutoras do "processo saúde-doença" (Czeresnia, 2012). Com as reflexões do médico e filósofo francês Georges Canguilhem sobre a vida, por ele concebida como "atividade normativa", houve uma inflexão no pensamento sobre a saúde. Em sua tese de doutorado em medicina (1943), intitulada Ensaio sobre alguns problemas relativos ao normal e o patológico, o autor introduziu o conceito original de normatividade biológica, 
enfrentando o desafio de teorizar sobre a saúde. Até então a ideia de normalidade associada a normas estáveis - e da doença como um desvio de normas fixas - não tinha sido satisfatoriamente colocada em questão. Mas, para Canguilhem, a normalidade consiste na capacidade de variação do organismo às mudanças circunstanciais do meio externo e interno, também variáveis, chamando a atenção para o fato de que a vida não é um conjunto de leis naturais (Portocarrero, 2009). Além disso, propôs distinguir normalidade e saúde, com base no argumento de que a normatividade seria intrínseca à vida. Conforme destaca Czeresnia (2012), a físico-química não considera um atributo irredutível à condição de ser vivo: ter a propriedade de discriminar entre o que é favorável ou desfavorável à sua preservação, criando normas para perseverar.

3 Com o conceito de normatividade, central em sua obra, Canguilhem delineou as noções de saúde e de patológico. Em sua perspectiva, a saúde é uma norma de vida superior, que corresponde à capacidade dos viventes de superar a doença e as modificações do meio, criando suas próprias normas. 0 patológico não é entendido como ausência de norma, mas uma normatividade restrita, uma norma de vida inferior, uma redução da segurança biológica inicial. A doença consiste em um "comportamento de valor negativo para um vivente individual, concreto, em relação de atividade polarizada com seu meio" (Canguilhem, 1943/1996, p. 150, tradução livre). Dito de outro modo, a doença é, ainda, uma expressão da vida, mesmo que empobrecida pela perda da capacidade de tolerar qualquer desvio das condições de existência. Consequentemente, o estado patológico é sempre definido a partir da experiência individual e subjetiva, não podendo ser estipulado por nenhum critério puramente externo e objetivo. Compreender o estado patológico exige sempre um diálogo com aquele que vive a experiência de sofrimento e impotência, um "sentimento de vida contrariada" (Canguilhem, 1943/1996, p. 85, tradução livre) em seu corpo, pois ela é parcialmente inacessível aos outros.

4 Portanto, trata-se de uma noção de saúde referida simultaneamente à experiência individual e ao meio. Para Canguilhem, há uma estreita ligação entre normatividade e individualidade biológica - entidade que, para ele, é melhor representada pelo organismo e não por uma célula ou um órgão. Assim, pensar a saúde só tem sentido com referência ao organismo: "É a razão pela qual propomos, ao contrário dos costumes médicos atuais, que é incorreto falar de órgãos doentes, de tecidos doentes, de células doentes" (Canguilhem, 1943/1996, p. 119, tradução livre). Por outro lado, somos obrigados a conviver em condições dadas, impostas e muitas vezes não desejadas, isto é, com as "infidelidades do meio": destruição ecológica, distribuição perversa da riqueza, condições e formas de organização do trabalho desfavoráveis ou inaceitáveis, falta de segurança, analfabetismo ou escolaridade precária, alimentação deficiente etc. Diante desses problemas concretos, Canguilhem insiste no caráter relacional da saúde e da doença, não temendo retomar alguns postulados da medicina grega (Safatle, 2011). Afasta-se assim de uma concepção substancial ou essencialista, indicando que a capacidade normativa do indivíduo se desenvolve na relação que estabelece com o meio (Giroux, 2010), chamando a atenção para a polaridade dinâmica da vida. Ou seja, a saúde está muito ligada tanto ao meio em que vivemos, quanto à capacidade que temos e desenvolvemos (individual e coletivamente), para transformálo segundo nossos interesses e valores, (re)afirmando nossa potência de vida.

5 Em seguida à sua tese, a relação entre vivente e meio foi cuidadosamente analisada $\mathrm{e}$ apresentada em uma de suas Conferências (1946-47) no Collège philosophique (O vivente 
e seu meio), só publicada pelo autor em 1965 no livro o conhecimento da vida. Nesse evento esclarece que problemas colocados pelo meio (geográfico, laboral etc) podem ser sim reconfigurados, uma vez que o homem, enquanto ser histórico, é capaz de recriá-lo. Então, embora o organismo não se encontre em harmonia predefinida com o meio (Portocarrero, 2009), a relação que se estabelece pode ser caracterizada como um debate (de normas), em que o ser vivo traz suas próprias normas de apreciação das situações. Porém, para o autor, esta relação não consiste essencialmente, como se poderia crer, numa relação de luta ou oposição, pois uma vida que se afirma contra é uma vida já ameaçada.

6 Em 1988, em Conferência na Universidade de Estrasburgo, Canguilhem (2005) avança ainda mais em suas reflexões sobre a relação entre vivente e meio, declarando que a saúde do corpo exprime a qualidade dos poderes que o constituem. A partir desse enunciado, esclarece que esse corpo é, ao mesmo tempo, um dado e um produto, sendo a saúde, simultaneamente, um estado e uma ordem. Um dado porque é um efeito singular dos componentes de um patrimônio genético (genótipo), e um produto devido à sua inserção em um meio específico, seu modo de vida escolhido ou imposto, que contribui para singularizar suas capacidades (fenótipo). Como estado do corpo dado, a saúde é a prova de que ele é possível, sendo sua fragilidade (ou má saúde) compreendida como a limitação do poder de tolerância e de compensação das agressões do meio ambiente, isto é, a restrição das margens de segurança orgânica. Como expressão do corpo produzido, a saúde é, simultaneamente, a garantia contra o risco e a audácia de corrê-lo. Está ligada ao sentimento da capacidade de ultrapassar capacidades iniciais.

7 Foi ainda na Conferência de Estrasburgo que Canguilhem (2005) afirmou que a saúde não se constitui em objeto de especialistas, não é estabelecida por cálculos, leis ou frequências estatísticas, mas, ao contrário, que se trata de um "conceito vulgar", no sentido de que está ao alcance de todos e pode ser enunciado por qualquer um. $\mathrm{Na}$ medida em que todos nós vivenciamos a dor e o sofrimento, assim como vivenciamos silenciosamente esse fenômeno que damos o nome de saúde, nos deparamos com uma dessas questões com a qual estamos necessariamente envolvidos, sendo esta também, portanto, uma questão filosófica (Caponi, 1997). Sim, a saúde é vivida e de forma silenciosa: "O homem sadio que se adapta silenciosamente às suas tarefas, que vive sua verdade de existência na liberdade relativa de suas escolhas, está presente na sociedade que o ignora. A saúde não é somente a vida no silêncio dos órgãos, é também a vida na discrição das relações sociais" (Canguilhem, 2005, p. 44).

8 Mas se a doença é primeiramente uma experiência vivida negativamente por um sujeito antes de se tornar um conceito empírico (Canguilhem, 1943/1996), o saber científico é necessário para identificar sua natureza. $O$ ponto central aqui é a articulação entre experiência e conhecimento, sinalizando-se que esse saber científico também foi desenvolvido a partir de experiências prévias de sujeitos doentes. De acordo com Canguilhem (2005, p. 48) o reconhecimento da saúde como verdade do corpo, no sentido ontológico, deve admitir a presença da verdade no sentido lógico (isto é, da ciência), como um anteparo.

9 Entretanto, a Organização Mundial da Saúde (OMS), criada em 1948, precisou delimitar seu espaço de atuação através de uma certa definição de saúde, que parece refletir a aspiração ao direito a uma vida plena e sem as privações do pós-guerra (Scliar, 2007). Tal definição, embora tenha o mérito de explicitar que a saúde não é apenas a ausência 
de doença ou enfermidade, numa perspectiva positiva da saúde, é bastante criticada por caracterizá-la como uma condição certamente inatingível para os seres humanos: "um completo estado de bem-estar físico, mental e social". Para Caponi (1997), a ideia de bem-estar, assim como de equilíbrio, associa-se ao conceito de normalidade, em termos de valores sociais. Ao não distinguir saúde e normalidade, patologia e anomalia, essa definição permite que qualquer variabilidade seja considerada como patológica e, consequentemente, como medicável. Em outra direção (funcionalista), Boorse (1977) também se opõe a essa definição com sua teoria bioestatística da saúde (TBS), que se baseia exclusivamente em dados objetivos ligados a fatos biológicos da natureza, desconsiderando a capacidade normativa dos seres vivos e recusando todas suas dimensões valorativas.

10 Ainda como contraponto à definição da OMS e na mesma linha do pensamento de Canguilhem, temos a contribuição de Dejours (1986), para quem a saúde é antes de tudo uma sucessão de compromissos com a realidade. E, complementando: "a saúde é a liberdade de dar a esse corpo a possibilidade de repousar, é a liberdade de lhe dar de comer quando ele tem fome, de fazê-lo dormir quando ele tem sono, de fornecer-lhe açúcar quando baixa a glicemia. É, portanto, a liberdade de adaptação". (Dejours, 1986, p. 11). Tais compromissos com a realidade remetem à articulação entre normas biológicas (vitais) e normas sociais, que foi objeto de análise de Canguilhem (1966) na segunda parte do livro 0 normal e o patológico (Novas reflexões relativas ao normal e o patológico), em especial no tópico Do social ao vital.

11 Como sinaliza Le Blanc (1998), a normalização operada no social difere das normas vitais porque resulta de escolhas e decisões exteriores ao objeto normalizado. Há, entretanto, um processo permanente de normatividade social, cujo horizonte é o das normas valorizadas pelos sujeitos. É nesse sentido que se inscreve a discussão de Canguilhem (1947/2001, (p. 116) a respeito da análise do sociólogo do trabalho Georges Friedmann, exposta no livro Problemas humanos do maquinismo industrial, publicado na França em 1946: “As reações operárias à extensão progressiva da racionalização taylorista, revelando a resistência do trabalhador às 'medidas que lhe são impostas do exterior' devem, portanto, ser compreendidas tanto como reações de defesa biológica quanto como reações de defesa social, e nos dois casos, como reações de saúde".

Na concepção de saúde de Nordenfelt observa-se uma tentativa de tratar as tensões entre normas biológicas e sociais de forma mais precisa. Inscrita na Teoria da Ação, mas inspirada em Canguilhem e outros autores (como no filósofo finlandês Ingmar Pörn), Nordenfelt (1987) define a saúde com base na articulação de três elementos: o agente e sua capacidade de agir; seus objetivos vitais; circunstâncias dadas. $\mathrm{O}$ autor procura refinar a noção de capacidade de Canguilhem, elegendo-o como conceito-chave de sua teoria, ao mesmo tempo que introduz uma concepção de doença como disfunção em relação às expectativas individuais e sociais, ou seja, como disfunção ligada às atividades da vida (Gaudenzi, 2016). Assim, conforme Giroux (2010), a normatividade para esse autor, diferente do que foi elaborado por Canguilhem, é acima de tudo associada, à intencionalidade de um sujeito (e não à biologia). Em sua concepção, a ideia de fronteira (saúde versus doença) cede lugar à ideia de gradação, sendo a saúde (física e mental) avaliada em graus, tendo como referência o que é aceitável para a pessoa, pois o que é identificado como doença é dependente da experiência subjetiva (Gaudenzi, 2016). 
13 As críticas às limitações do modelo biomédico estão também na origem da área denominada Saúde Coletiva, desenvolvida na América Latina a partir da década de 1970, como resultado de um movimento que envolveu universidades, serviços de saúde e atores sociais, conduzindo à Reforma Sanitária Brasileira. Essas críticas levaram ao entendimento do binômio saúde-doença como um processo histórico-social, sendo a obra de Canguilhem uma referência nas publicações consideradas fundadoras da área, especialmente pela importância atribuída aos modos de vida (Ayres, 2006). Dessa interpretação decorre a expressão "processo saúde-doença" e o olhar sobre seus determinantes socioculturais e econômicos, que podem ser associados à noção de meio e de normas sociais do filósofo.

14 Entretanto, as distintas correntes de pensamento sobre o processo saúde-doença indicam compreensões específicas. Para Laurell (1982), a melhor forma de comprovar o caráter histórico desse processo se dá através do estudo de como ele ocorre nos grupos humanos, acrescentando que é determinante o modo como o homem se apropria da natureza em um dado momento, através do processo de trabalho. Essa visão estrutura o campo da Saúde do Trabalhador, que recusa os modelos considerados mecanicistas da Medicina do Trabalho e da Saúde Ocupacional. Outros autores sinalizam a complexidade dos fenômenos de saúde, doença, sofrimento e morte (Sabroza, 2001; Almeida Filho, 2011). Nessa linha, segundo Sabroza (2001), o processo saúde-doença ocorre na interseção da lógica da reprodução da vida e da lógica da produção econômica, se expressando tanto individualmente, quanto nos grupos populacionais, como nas sociedades (nesse nível, como problemas de saúde pública).

De acordo com Ayres (2016), a influência de Canguilhem foi se diluindo e diversificando na Saúde Coletiva, mas nem por isso perdendo sua relevância. Pode-se afirmar, por exemplo, que o conceito de normatividade se alinha com o reconhecimento, nesta área, da importância da participação social nas lutas pela saúde.

Enfim, a concepção positiva de saúde, com atenção para a capacidade normatividade do ser vivo - que se manifesta também através de formas de mobilização orientadas por valores pertinentes à dignidade da vida - apresenta uma grande fertilidade. Especialmente para as intervenções e pesquisas que visam transformar os modos de vida e trabalho com foco na atividade.

\section{BIBLIOGRAFIA}

Ayres, J. R. C. M. (2016). Georges Canguilhem e a construção do campo da saúde coletiva brasileira. Intelligere, Revista de História Intelectual, 2, 1 [2], 138-154. https://doi.org/10.11606/issn. 2447-9020.intelligere.2016.115732

Almeida Filho, N. (2011). o que é saúde? Rio de Janeiro: Editora Fiocruz. https://doi.org/ 10.7476/9788575413432

Boorse, C. (1977). Health as a theoretical concept. Philosophy of Science, 44, 542-573. https:// doi.org/10.1086/288768 
Caponi, S. (1997). Georges Canguilhem y el estatuto epistemológico del concepto de salud. História, ciência e saúde - Manguinhos, 4, 2, 287-307. https://doi.org/10.1590/ S0104-59701997000200006

Canguilhem, G. (1943/1996). Le normal et le pathologique. Paris: PUF.

Canguilhem, G. (1965/2003). La Connaissance de la vie. Paris: Vrin.

Canguilhem, G. (2005). A saúde: conceito vulgar e questão filosófica. In: Escritos sobre a Medicina(p. 35-48). Rio de Janeiro: Editora Forense Universitária.

Canguilhem, G. (2001). Meio e normas do homem no trabalho. Pro-posições, 12, 2-3, 35-36.

Czeresnia, D. (2012). Categoria vida: reflexões para uma nova biologia. São Paulo: editora Unesp; Rio de Janeiro: Editora Fiocruz.

Dejours, C. (1986). Por um novo conceito de saúde. Revista Brasileira de Saúde Ocupacional, 14, 7-11.

Gaudenzi, P. (2016). Normal e Patológico no naturalismo e no normativismo em saúde: a controvérsia entre Boorse e Nordenfelt. Physis Revista de Saúde Coletiva, 26, 3, 747-767. https:// doi.org/10.1590/s0103-73312016000300003

Giroux, E. (2010). Après Canguilhem : définir la santé et la maladie. Paris: PUF.

Laurell, A. C. (1982). La salud-enfermedad como proceso social. Revista Latinoamericana de Salud, 2 , 7-25.

Nordenfelt, L. (1987). On the nature of health: an Action-Theoretic Approach. Dordrecht: D. Reidel Publishing Company. https://doi.org/10.1007/978-94-015-7768-7

Portocarrero, V. (2009). As ciências da vida: de Canguilhem a Foucault, Rio de Janeiro: Editora FIOCRUZ. https://doi.org/10.7476/9788575414101

Sabroza, P. C. (2001). Concepções de Saúde e Doença. Texto de Apoio ao módulo I do Curso de Especialização em Gestão de Sistemas e Serviços de Saúde - EAD. Rio de Janeiro: ENSP.

Safatle, V. (2011). O que é uma normatividade vital? Saúde e doença a partir de Georges Canguilhem. Scientiae Studia, 9, 1, 11-27.

Scliar, M. (2007). História do Conceito de Saúde. Physis Revista de Saúde Coletiva, 17, 1, 29-41. https://doi.org/10.1590/S0103-73312007000100003

\section{ÍNDICE}

Temas: o Dicionário

\section{AUTOR}

\section{JUSSARA BRITO}

Fundação Oswaldo Cruz - Escola Nacional de Saúde Pública Sergio Arouca Rua Leopoldo Bulhões 1480, Manguinhos Rio de Janeiro - RJ, CEP 21041-210, Brasil jussara@ensp.fiocruz.br 